\title{
NOISE IMPACT IN POWERED RESPIRATORS
}

\author{
Klaus-Dieter Fröhner, Ze Li \\ Institute of Ergonomics, University of Technology Hamburg-Harburg, \\ Eissendorfer Strasse 40, 21073 Hamburg, Germany
}

\begin{abstract}
In respirators the users are closely linked with the apparatus. The new types of respirators use powered ventilators so that the technical layout and the used elements have strong effects on the users. The most unwanted effect is noise that influences not only the hearing ability of the user but also impairs the communication between users. This study aims at a systematic investigation of influencing factors based on a study evaluating methods for measurements. It covers the main actual products of respirators on the market and after measuring gives a systematic approach to what can be changed to improve the noise impact in powered respirators.
\end{abstract}

\section{INTRODUCTION}

Workers in all industry, agriculture, rescue service, civil defence and armed force need respiratory protection when they work in exceptional conditions. Battery powered respirators can offer breathing protection and safeguard workers' health and working capacity. Producers constantly improve the comfort, weight, durability and reliability of its breathing apparatus. But from ergonomical viewpoints the product development of powered respirators is not really user-oriented and the design and the construction of these powered respirators cannot be regarded as satisfactory. In practice noise in powered respiratory systems causes stress for the users and has an impact upon the communication between the users of powered respirators (Fröhner, 1989; Li, 1996). Therefor, a schema for measurements, to evaluate powered respirators, was developed and tested by different respirators (Fröhner, 1998). This study has been enhanced by measuring more respirators that cover the range of products on the market so that more systematic results can be drawn.

\section{NOISE MEASUREMENTS AND ANALYZING}

The most common complaint about noise is that it interferes with or masks speech signals. In the using of powered respirators, noise with high sound level is a source of stress. The users feel disturbed by noise if the exchange of information is strongly impeded. Indeed, the masking of speech by noise greatly reduces the performance of work and is a cause of accidents in industry (Kryter, 1985, Neise, 1976). For the purpose of noise reduction in respiratory systems, it is necessary to determine the compounds that can cause the noise. This can be in general the used elements, the guideway of the air and the layout of the systems. So we will describe the systems by the following and one example is shown in figure 1:

- Integrated or separated system: In an integrated system, ventilator and power pack are one unit with the breathing apparatus; in a separated system, ventilator and power pack are apart from the breathing apparatus. Workers normally wear it on the back.

- determined or undetermined guideway of the air in the breathing area: A determined guideway has a concrete inlet and a concrete outlet, sometimes with an outlet-valve; an undetermined guideway has a concrete inlet but no specific outlet. Furthermore the position of inlet and outlet is of importance.

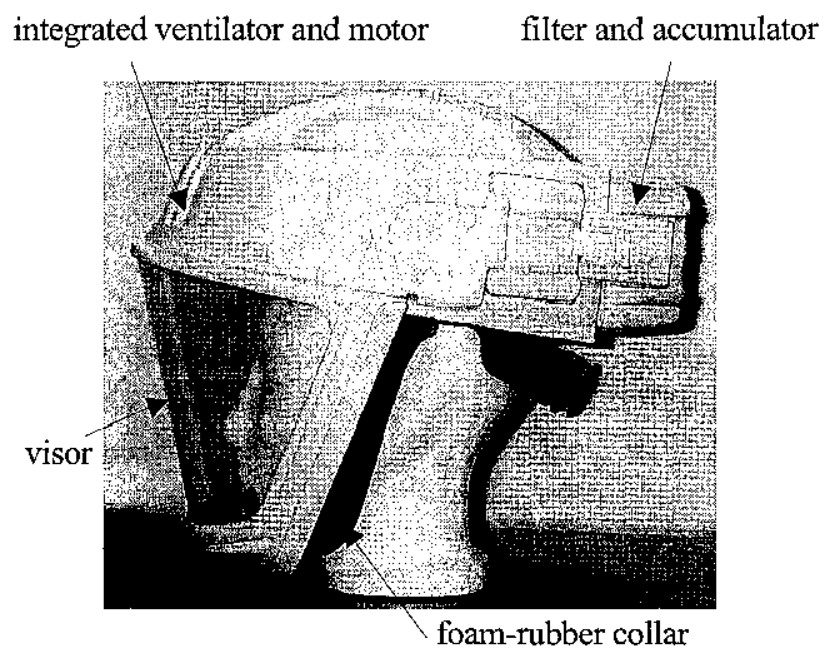

Figure 1: Open integrated system in form of a semihelmet with determined inlet of the air and an undetermined outlet via the foam-rubber collar

- closed or open system: In a closed system the whole head is protected (airhelmet). It is easier to seal this 
system to the outside via a flexible neck sleeve. In an open system the face is partially protected (face shield, lighthood with soft material covers partially head) and the head can be partially protected (airhood only with forehead protection, semi-helmet shown in figure 1). The ear is never included in an open system. The open systems are not easy to seal because the systems have to be adapted to the different shapes and measures of heads.

The analysis is based on the selected respirators. These were chosen because they show the newest trends of products on the market and cover the whole range of diferent layouts. Five separated and three integrated sysems are the basis for measuring and analyzing due to the situation that integrated systems are not offered in a variety that is shown by the separated systems.

\section{Measures of Noise Energy of the Ventilator}

The aerodynamic quality of the ventilator affects directly, by its acoustic characteristics, the communication between respirator users and comfort of powered respirator systems $(\mathrm{Li}, 1994)$. Therefor the sound power level was measured with a sound intensity analyzer (figure 2).

Sound power level $\mathrm{dB}(\mathrm{A})$

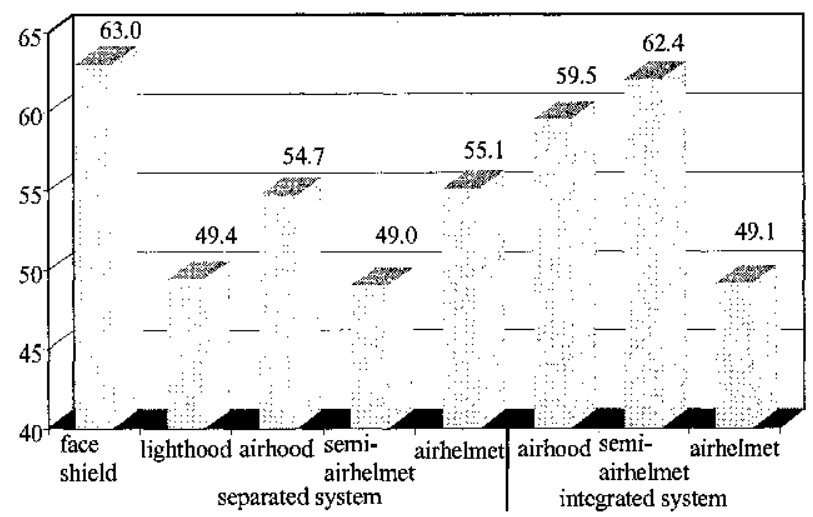

Figure 2: Sound power level of ventilator and power pack for separated systems and sound power level for the integrated systems

The results show that the range of the sound power level of separated and integrated systems is pretty much the same, this could not be assumed after the evaluative study (Fröhner, 1998).

The range of sound power level of all systems is very large with $14 \mathrm{~dB}(\mathrm{~A})$. The power pack for the face shield has the highest level. The reason for this is the inadequate dynamic quality of the ventilator and the lacking of damping when tightening the ventilator to the housing of ventilator and power pack. The not very stable housing is activated to vibrate. The housing of the lighthood and the semi-helmet in separated systems are very stable and the ventilators furthermore have a better dynamic quality.

The integrated systems have to be looked at in a different way because it is obvious that an integrated system has, apart from the housing, fragile elements. Therefor through the activation by the ventilator the noise level could be higher than that for the housing with ventilator and power pack. But the markedness of the level is the same because the used axial ventilators produce a less dynamic and more constant flow than the ones used in the separated systems. The reason for the two high levels for the integrated systems is inadequate damping for the ventilators and hard material for the corpus. The system with low sound power level is on the one hand better damped and on the other hand has a lower air flow.

\section{Measures of Noise Pressure Level at the Users' Ear}

After having depicted the technical elements of sound power it is necessary to carry out an analysis of how this effects the user. Therefor a frequency analysis near the ear was carried out. The values measured are a results of the sound power level of the ventilator, the vibration of the air column in the apparatus, the vibration of the housing and the apparatus as well of the noise developing when leaking through small openings between face and systems.

For this investigation, one male and one female were selected. The male subject is 31 years old and 182 $\mathrm{cm}$ in height. The female subject is 32 years old and 165 $\mathrm{cm}$ in height. The selected samples represent the German male and female populations by stature as closely as possible. There were no irregularities concerning the hearing abilities. The measurement points were about 3 $\mathrm{cm}$ to the ear of the subjects. This means that they were not within the closed systems.

For the semi-airhelmet as an integrated open system (figure 1) the high level is determined through the inadequate damping, the hard material and the undetermined outlet via the foam-rubber near the ear (figure 3 ). The relative high level of the airhood as an integrated open system is due to inadequate damping and the undetermined outlet via foam-rubber near the ear eased by an outlet on the bottom. The high level of the face shield system could be expected because of the characteristics of the ventilator and the housing construction as well as the housing material. Additionally it is caused by the 
undetermined outlet of the air through the openings between the face and the frame of the face-shield.

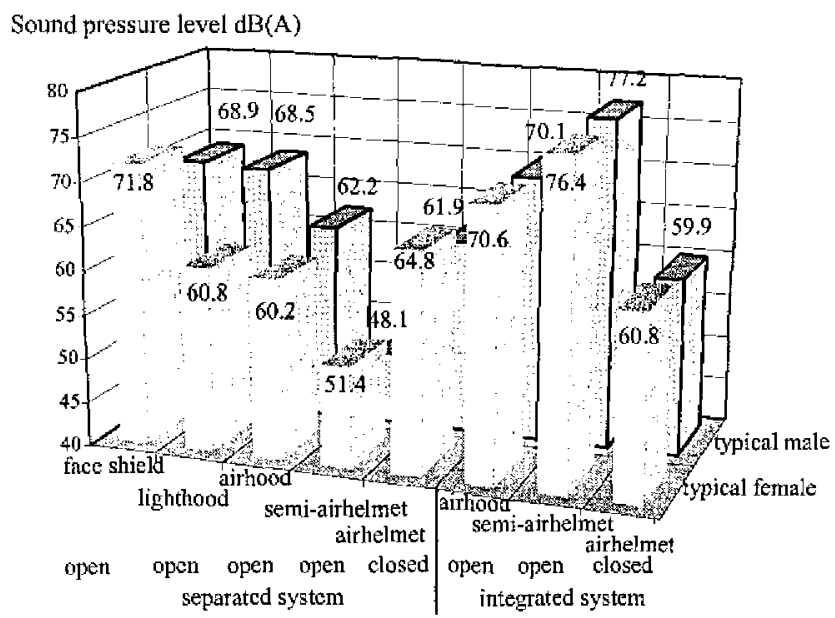

Figure 3: Sound pressure levels of two subjects at the ear

The lowest sound pressure level can be stated for the semi-airhelmet as a separated system. The reasons for this low level are threefold: a. the described low sound power level of the ventilator and power pack; $b$. the determined guideway of air in the breathing area with an outlet-valve and c. the good sealing between face and breathing apparatus.

Lighthood and airhood as open separated systems and the two airhelmets as closed systems have pretty much the same level although they have completely different layouts: The airhelmet as a separated closed system is made up out of hard, heavy material with the outlet including a valve on the back-side, whereas the airhelmet as an integrated system is partially produced out of soft material and has an outlet with valve at the bottom. The lighthood and airhood have pretty much the same sound pressure level for the typical female. In this case the used soft material for the sealing is adequate.

Looking at the differences between typical female and male there is only one obvious difference. This is the only system without hard and stable frame or elements in breathing apparatus (lighthood).

\section{AUDIOTHRESHOLD SHIFT MEASUREMENT}

High noise level at the ear can impair the hearing process by wearing a respirator. To confirm the noise masking effect, audiotests were carried out in the sound absorption chamber. The threshold of audibility is determined through audiometer by using a respirator. No headphone was used in the tests.

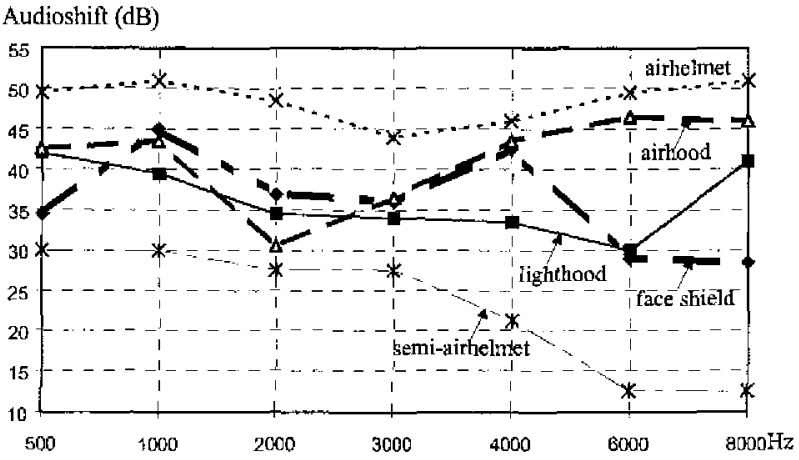

Figure 4: Threshold shifts of the different respirators with separated system

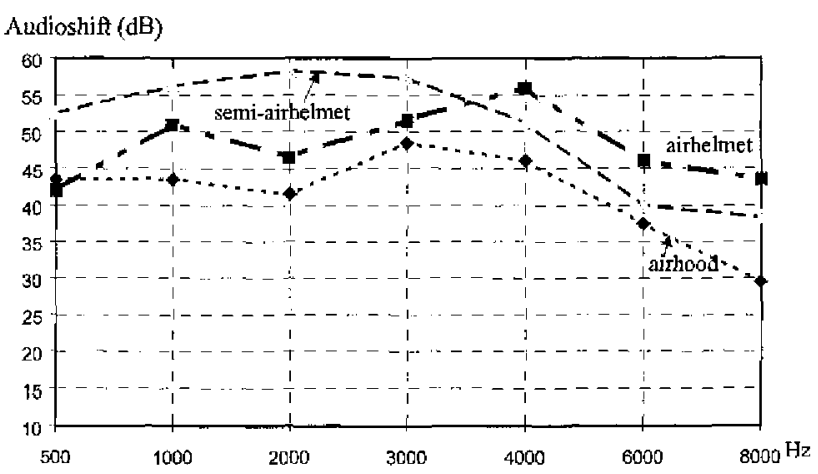

Figure 5: Threshold shifts of the different respirators with integrated system

In figure 4 it can be seen that the level for the threshold shifts in separated systems is the highest for the airhelmet. This is because of the layout in which the ear is included in the system. The semi-airhelmet has the lowest levels; the impairing from $6000-8000 \mathrm{~Hz}$ is even very low. So it can be stated that the layout of the guideway of the air and of the valve as well as the used material for the sealing is appropriate.

In figure 5 it can be seen that the level for the threshold shifts in integrated systems is very high. The airhelmet, as a closed system with the ear in it, does not show the highest level. This has two reasons: a. the layout of the semi-airhelmet is far from satisfactory and the ear thereby is having a high load and $b$. the closed system is nicely designed out of soft and hard materials.

\section{DETERMINATION OF SOUND TRANSMISSION LOSS}

By wearing a powered respirator there is not only the problem of interfering by noise from the outside, but also the problem of sound transmission loss, when giving information to the outside. The investigations were carried out in a sound absorption chamber in the labora- 
tory. A small loudspeaker was located in the mouth of a head manikin. The white noise was used as a standard sound source. The sound pressure level outside the system was measured at a distance of $1 \mathrm{~m}$ and fixed at 78 $\mathrm{dB}(\mathrm{A})$. Thereafter the sound transmission at a distance of $1 \mathrm{~m}$ was determined with the manikin wearing the respirators.

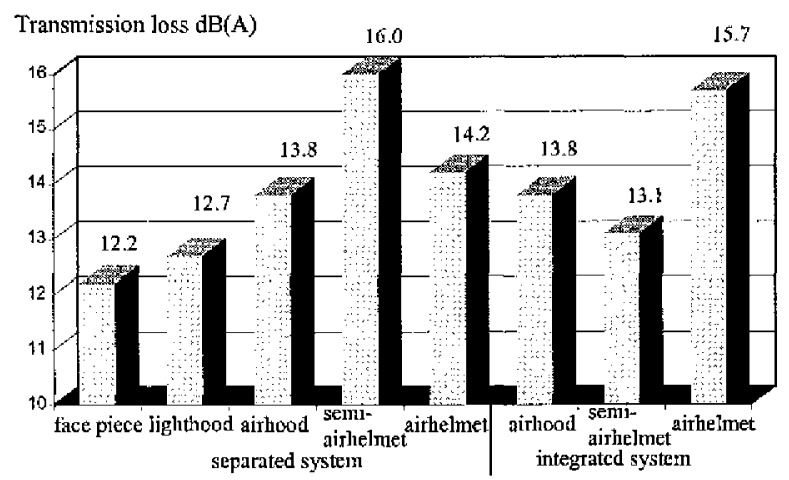

Figure 6: Transmission loss of sound of the respirator systems by the sound source $78 \mathrm{~dB}(\mathrm{~A})$

The highest sound transmission loss can be stated for the systems with little leakage. Furthermore both systems (semi-airhelmet as an open separated system and airhelmet as an integrated closed system) have outletvalves that seal the systems of from the outside. Face shield and lighthood, the systems with the most leakage because of the bad sealing between the face and the apparatus, show the lowest transmission losses of 12.2 or $12.7 \mathrm{~dB}(\mathrm{~A})$. The measurements were realized with a ventilator running and a ventilator not running. The differences realized were smaller than $1 \mathrm{~dB}(\mathrm{~A})$.

\section{CONCLUSIONS}

The following inferences can be drawn out of the measurements and the analysis:

- It seems to be very hard to develop an integrated system that has little influence on the user. This is obvious because the source of the noise is on the head and furthermore causes back bone transmission.
- Open systems seem to be more appropriate for users. This is because the ear in closed systems is having a high load.

- Determined guideways for the air seem to be necessary to realize systems with low noise level at the ear.

- Good sealing can not only reduce evidently the noise level at the ear but also enhance the transmission loss for communication.

- Selection of appropriate materials for the sealing and cover of the breathing apparatus is necessary.

- One important prerequisite to realize satisfactory systems is little activation by dynamic processes.

- One further very obvious prerequisite is the selection of materials with good damping abilities.

In practice all inferences have to be looked at with different influences when designing a respirator.

\section{References}

Fröhner, K.-D. and Stefan, R.: Probleme bei der Verwendung und Verbesserung von Atemschutzhelmen. StaubReinhaltung der Luft, 49 (1989), p. 461-466

Fröhner, K.-D. and Li, Z.: Noise Effects on Communication between the Users of Powered Respirators, in: Ergonomic Practice and Its Theory, Proceedings of the 5th Pan-Pacific Conference on Occupational Ergonomics, UOEH-Kitayushu 1998, ISSN 1344-1876, P.132-135

Kryter, Karl D.: The Effects of Noise on Man, ACADEMIC PRESS INC. (LONDON) LTD., ISBN 0-12-427460-9, 1985

Li, Z.: Auslegung von Atemschutzhelmen unter Beachtung menschlicher Eigengesetzlichkeiten und technischer Einflußgrößen. ISBN: 3-18-311418-8, VDI Vetlag, Düsseldorf, 1994

Li, Z. and Fröhner, K.-D.: Noise Measurements and Noise reduction in a Personal Respiratory Protective System. Advances in Occupationat Ergonomics and Safety I $(2 \mathrm{Vol}$.) 1996, pp. 686-691

Neise, W.: Noise reduction in centrifigal fans: a literature survey. Journal of sound and vibration, 1976, 45(3), pp. $375-403$ 